\title{
Will prevention be better than cure? The challenge of retaining health staff in the public health sector in Sri Lanka
}

\author{
PK Buddhika Mahesh ${ }^{1 *}$, M Wasantha Gunathunga ${ }^{2}$, S Mahendra Arnold ${ }^{3}$, L Sinha D de Silva ${ }^{1}$, \\ Monika P Wijeratne ${ }^{4}$, Janaka Weragoda ${ }^{3}$ \\ ${ }^{1 *}$ Postgraduate Institute of Medicine, University of Colombo, Sri Lanka; ${ }^{2}$ Department of Community Medicine, Faculty \\ of Medicine, University of Colombo, Sri Lanka; ${ }^{3}$ Office of the Regional Director of Health Services, Colombo, Sri Lanka; \\ ${ }^{4}$ Office of the Provincial Director of Health Services, Western Province, Sri Lanka \\ "Correspondence: buddhikamaheshpk@gmail.com
}

DOI: https://doi.org/10.4038/jccpsl.v24i1.8143

Received on: 23 February 2018

Accepted on: 15 April 2018

Public health sector contributes to better health indicators especially in the developing countries. Community medicine is a branch of medicine related to public health, which renders a silent service in achieving long-term health benefits. Medical professionals in community medicine together with other staff members in public health had contributed immensely to the century-old health unit system of Sri Lanka, despite being a lower-middle income country. However, many challenges faced by the public health staff that discourage their entering into and retention in the public health system have been identified. Unless these issues are addressed timely, the gradual collapse of the public health system might not be avoided. This article elaborates these aspects and discusses the potential strategies to retain health staff in public health.

The World Health Organization (WHO) defines health as 'a state of complete physical, mental and social wellbeing and not merely the absence of disease or infirmity' (1). It implies that a health system must target improving the 'well-being' of people and not only on 'curing' diseases. Since health is influenced by many societal factors, raising a person's wellbeing essentially needs community-based strategies. These include aspects such as identification of risk factors, planning and implementing community level interventions, surveillance of health related conditions, provision of domiciliary care, health promotion, and monitoring and evaluation of health interventions. Public health sector is the driving force for health especially in developing countries (2).

Community Medicine which was developed as a branch of the medical field in the last century, mainly deals with public health (3). Compared to the many other specialties which provide care for the individual patients in curative settings, community medicine bridges the dynamics in the disease-wellbeing process extending the focus beyond institution-based care. Hence, community medicine, which is the medical aspect of public health enables proving that prevention is better than cure (4). Yet, the health staff engaged in public health including the practitioners of community medicine faces several demotivating factors compared to the curative setup. Firstly, this field does not seem to be glamorous in the initial look (5). Unlike a patient visiting hospital with a lower respiratory tract infection and returning home cured in a few days, the public health interventions such as reduction of low birth weight may not always provide such quick results. Secondly, unless the results of public health interventions are analysed over a period of time, it may not be possible to realize the impact. As an example, improving the immunity as a result of vaccination programs and how many communicable diseases have been controlled may not be obvious at a glance. Thirdly, the health 
staff engage in public health may not receive some of the privileges and recognition that they would have received had they been in the curative sector. A consultant in community medicine who needs to visit the field activities frequently would not have the necessary logistic facilities such as transport and the required medical and other staff under him. A field staff member would have to work outside the routine duty hours to assist a needy pregnant mother without being eligible for additional payments.

Being a lower-middle income country, Sri Lanka has shown promising health parameters (6). The maternal mortality ratio has decreased closer to 30 per 100,000 live births and under-five mortality rate to 10 per 1000 live births (7). Three main reasons for this success have been; free healthcare, free education and having a well-organized public health infrastructure (8). The health unit system was in action in Sri Lanka for nearly a century (9). Currently, there are around 341 health units named medical officer of health $(\mathrm{MOH})$ areas delivering public health related services (10). The $\mathrm{MOH}$ team includes medical officers, supervisory officers and field staff members. Of the latter, public health midwives (PHM) are involved mainly in maternal and childcare services and the public health inspectors (PHI) mainly on the disease surveillance, food safety, environment and occupational health services (11). All these are paid officers who have been trained in the respective areas of work. Services are delivered at the field, clinic as well as at the household levels. These field staff members are technically guided by the board certified specialists in community medicine, the consultant community physicians who have been posted at central, provincial and district levels.

It has been proposed to adopt a 'community healthcare worker' concept in order to coordinate the public health related activities even in high-income countries (12). It is noteworthy that Sri Lanka being an island of $65,000 \mathrm{~km}^{2}$ in the Indian Ocean has been practising this mode of care for nearly hundred years. Yet, there are some uncertainties growing regarding the future of this setup. A decreasing trend in medical officers opting for community medicine as a specialty is one such concern (13). A significant number of those entering into the specialty of community medicine do not continue to become specialists. Many medical officers prefer to work in the curative sector than in public health beacuse of the additional responsibilities, such as managing finances in the latter without any additional privilege (14). The influx of PHMs and PHIs into the system has been decreased over the years. For the same qualifications, there are many attractive job opportunities in the private sector. Many who remain as public health staff are near their retirement age. At the end of 2017, in the field care services of the Western Province, nearly one fourth of the PHM areas and $40 \%$ of the PHI areas were vacant (15). The presence of vacant areas, though being covered up by a staff member in an adjacent area, causes dilution of the coverage of services.

The value of public health should never be taken for granted. Investing on public health as a worthy cause has been highlighted in the developed countries (16). The governments should take measures to uplift the public health infrastructure. Budgetary allocations for public health activities must be regarded as a priority. Public health experts must be consulted in collaborative policy planning. Rather than been limited to routine practices, like in communicable disease control, innovative strategies must be encouraged and appreciated.

In glamorizing the scope of the PHMs and PHIs, several measures are suggested. Bottle necks of their training needs must be identified, and local or provincial training centers should be established. Out of date policies such as the inadequate amount paid as their 'office allowance' must be revisited. Modern technological advances must be incorporated into their job functions in order to prevent them getting rejected within the advancing communities.

In relation to the medical officers, moulding of favourable attitudes towards public health must be targeted from the undergraduate period. The vision of postgraduate training should include developing a generation of community-based practitioners without being limited to an institution-based component (17). Medial officers must be encouraged to undertake the public health centred specialties like community medicine (4). Sub-specialties of this field must be created. Publication of literature in relation to public health must be promoted. Efforts must be implemented in glamorizing public health and attracting medical officers and workforce towards entering the vacancies in this field (18). The logistic facilities must be uplifted and a supportive environment should be created for them to be retained in public health. The job descriptions and duty lists must be timely updated. 
In conclusion, retaining of staff in public health sector has become a challenge as the influx is becoming lesser than the amount leaving it. This is influenced by several demotivating factors, which must be reverted with immediate policy reforms. The well-laid public health infrastructure has been a blessing, which has enabled this small island nation in achieving commendable health standards. Yet, if immediate action is not taken, Sri Lanka would face a gradual deterioration of this treasure, the consequences of which would be apparent in decades to come.

'Things are valued by humans at two times; before they become ours and once we have lost them'. The sole wish of the remaining committed staff members is that the latter would never be true for public health.

\section{Author Declarations}

Competing interests: All the authors are either specialists or trainees in community medicine and staff of the public health system.

Ethics approval and consent: Not applicable. The manuscript does not contain any personal details at individual level.

Funding: Not applicable.

Ackowledgements: The authors like to acknowledge Dr Indrani Godakanda and Dr Saman Pathirana for their support extended.

Author contributions: All authors were involved in the planning of the manuscript. PKB drafted the first version and $\mathrm{MW}, \mathrm{SM}$ and SD reviewed it. MW and JW were involved in revising the article.

\section{References}

1. Misselbrook D. W is for Wellbeing and the WHO definition of health. British Journal of General Practice 2014; 64(628): 582-582.

2. Tandi TE, Cho Y, Akam AJ-C, Afoh CO, Ryu SH, Choi MS, Kim K, Choi J. Cameroon public health sector: shortage and inequalities in geographic distribution of health personnel. International Journal of Equity \& Health 2015; 14(1): 43.

3. Shewade H, Jeyashree K, Chinnakali P. Reviving community medicine in India: the need to perform our primary role. International Journal of Medicine \& Public Health 2014; 4(1): 29.

4. Mahesh PKB, Arnold SM, Gunathunga MW, Weragoda J. Unknown co-players in healthcare: recognizing the available services of the public-health sector. The Official Newsletter of Sri Lanka Medical Association- November 2017; 10(11): 18-24.

5. Yesalis CE, Politzer RM, Holt H. Fundamentals of US Health Care: Principles and Perspectives (1st edition). US: Delmar Cengage Learning, 2012.

6. Ministry of Health. Public Health Success in Sri Lanka. Colombo: Ministry of Health, 2017.

Available from: http://www.searo.who.int/srilanka/ documents/policybriefsfinal.pdf?ua $=1$.

7. WHO. WHO Statistical Profile. Countries-Sri Lanka. Geneva: World Health Organization, 2015.

Available from: http://www.who.int/gho/countries/ lka.pdf?ua $=1$.

8. Prasad R \& Dasgupta R. Missing midwifery: relevance for contemporary challenges in maternal health. Indian Journal of Community Medicine 2013;38(1): 9.

9. Hewa S. Sri Lanka's Health Unit Program: A Model of "Selective" Primary Health Care. Hygiea Int An Interdiscip J Hist Public Heal. 2011; 10(2): 7-33.

10. Medical Statistics Unit. Annual Health Bulletin 2015. Colombo: Ministry of Health, 2017.

11. Perera MN, Guruge ND, Gunawardena NS. Knowledge on health promotion approach among public health midwives in a district in Sri Lanka. Journal of the Postgraduate Institute of Medicine 2015; 2: 11.

12. Singh P \& Chokshi DA. Community health workers: a local solution to a global problem. New England Journal of Medicine 2013; 369(10): 894-896.

13. GMOA. Good Intern Programme 2013: research findings. Colombo: Ministry of Health, 2013.

14. Save the Children International. Investing in Children in Sri Lanka-Child Centric Resource Analysis Full Report. Colombo: Save the Children International Country Office, 2016.

15. Health Information Unit. Human resource profile: health staff in position by 31st December 2015. Colombo: Ministry of Health, 2016.

Available from: http://www.health.gov.lk/moh_final/ english/public/elfinder/files/publications/ HRMprofile2016.pdf.

16. Goodman RA, Bunnell R, Posner SF. What is "community health"? Examining the meaning of an evolving field in public health. Preventive Medicine 2014; 67(S1): S58-S61.

17. Mash R, Almeida M, Wong WCW, Kumar R, von Pressentin KB. The roles and training of primary care doctors: China, India, Brazil and South Africa. Human Resources for Health 2015; 13(1): 93.

18. Kumar R, Singh A, Gupta SN. Public health as a career option: postgraduate students' perspective. Indian Journal of Preventive Medicine 2013; 1(1). 